\title{
Retinoblastoma: a most unusual presentation - Case report
}

\author{
CN Pedro-Egbe M.B;B.S. FMCOph, IO Chukwukah M.B;B.S. FMCOph, UN Okorie M.B;B.S, M \\ Arowolo M.B;B.S \\ Department of Ophthalmology, University of Port Harcourt Teaching Hospital, Port Harcourt, Nigeria
}

\section{ABSTRACT}

Background: Retinoblastoma is the most common intraocular tumour in children, with the average age at diagnosis varying from 12 months in bilateral cases to 23 months for unilateral tumours. Extraocular disease has a far lower survival rate than the intraocular one. In the developed world, more than $90 \%$ of patients with retinoblastoma survive, however in the developing world, where retinoblastoma exists primarily as an extraocular disease, relatively few patients survive because of late presentation and paucity of treatment options.

Presented here is the case report of a $4{ }_{2} /{ }_{2}$-month old male Nigerian baby, who presented with a 2-week history of rapidly progressive painful proptosis of the right eye. Examination revealed a firm fungating mass arising from the right orbit which had pushed the globe supero-nasally. There was severe right lower lid oedema and marked conjunctival chemosis inferiorly, but the cornea was clear. The patient also had right leukocoria. The left eye was normal. An ultrasound scan showed a huge right ocular tumour, solid in consistency with heterogeneous architecture, which appeared to be growing from the superior margin of the globe; the finding was reported to be consistent with retinoblastoma.

Due to the rapidly progressive and necrotic nature of the tumour, a lid-sparing modified exenteration was done. The histopathology findings were consistent with a diagnosis of undifferentiated retinoblastoma. About two weeks after surgery there was tumour recurrence but this regressed following commencement of chemotherapy by the paediatric oncology unit.

The tumour recurred despite aggressive chemotherapy and the patient eventually died 6 months later.

Conclusion: Retinoblastoma in Third World countries is still a fatal disease, unlike in developed countries where it has a survival rate of over $90 \%$. Poverty and non availability of sophisticated diagnostic tools make early detection difficult thus increasing mortality from the disease.

Key words: retinoblastoma, congenital, unilateral, rapidly progressive

\section{INTRODUCTION}

Retinoblastoma is the most common primary intraocular malignancy of childhood in all racial groups. ${ }^{1}$ In developing countries, advanced stages are common. The average age at diagnosis varies from 12 months in bilateral cases to 23 months for unilateral tumours. ${ }^{1}$ The incidence of retinoblastoma is estimated to be between 1 in 15,000 and 1 in 34,000 births. ${ }^{2,3}$

Retinoblastoma is a life-threatening disease and survival depends on how advanced the disease is at presentation. The survival rate for diagnosis of extraocular symptoms is far lower than for intraocular disease. In the developed world, more than $90 \%$ of patients with retinoblastoma survive. ${ }^{4}$ In the developing world, however, retinoblastoma exists primarily as an extraocular disease and relatively few patients survive because of late presentation and paucity of treatment options. ${ }^{5}$

Although leukocoria and strabismus are the most common presenting signs of retinoblastoma, a retrospective study by Abramson et al. identified 32 distinct presenting signs of retinoblastoma. ${ }^{6-8}$

A few other studies have also noted some distinct characteristics exhibited by children whose conditions were diagnosed in the first year of life. ${ }^{9,10}$ Not only are these children diagnosed at a younger age, their laterality is different (most commonly bilateral when diagnosed in the first year). In addition, they have a greater tendency to develop a subsequent intraocular tumour after treatment.

Early age at diagnosis does not guarantee an early stage of intraocular or extraocular disease; rather it is associated with significant mortality.

\section{CASE REPORT}

G.J is a four-and-half month-old male baby ( $6.4 \mathrm{~kg}$ weight) who presented at our outpatient clinic on $11^{\text {th }}$ April, 2008 with a 2-week history of rapidly progressive painful protrusion of the right eye. The patient was referred from the paediatric clinic of the same hospital. The mother reported that the child had normal eyes at birth and was doing well until 2 weeks prior to presentation when she noticed a small growth in the inferior part of the eye around the lower lid. Over the course of 2 weeks, the swelling rapidly increased in size causing protrusion of the right eye. The baby became very ill and restless, and was unable to breastfeed.

${ }^{*}$ Correspondence: Dr. Chinyere Nnenne Pedro-Egbe, Department of Ophthalmology, University of Port Harcourt Teaching Hospital, Port Harcourt, Nigeria • e-mail: cpegbe@weltekng.com 
There was no history of fever, redness of the eye, or trauma to the eye. Pregnancy and birth histories were uneventful but the child had neonatal jaundice at one week. His developmental milestones were appropriate for age. The patient was the first and only child of his parents (child's mother was a 19-year old secondary school leaver while the father was a second year undergraduate) and there was no known family history of retinoblastoma.

General systemic examination revealed a well-fed baby in obvious pain, afebrile (axillary temperature of $37.2^{\circ} \mathrm{C}$ ), not pale, anicteric but had a dry tongue.

External eye examination revealed complete ophthalmoplegia with severe right lower lid oedema and hyperemia; the upper lid was normal and freely mobile over the globe. The superior conjunctiva and sclera were white while in the inferior half, there was marked conjunctival injection and chemosis (fig. 1). Arising inferiorly was a firm fungating mass which had pushed the globe supero-nasally. The cornea was clear with a shallow anterior chamber and a mid-dilated unreactive pupil. There was leukocoria and no red reflex on funduscopy (fig. 1). There was complete ophthalmoplegia. The left eye was normal.

An initial diagnosis of right orbital cellulitis to rule out congenital retinoblastoma and embryonal sarcoma was made. The patient had already been started on systemic antibiotics (intravenous ceftriazone $50 \mathrm{mg} / \mathrm{kg} /$ day, genticin $5 \mathrm{mg} / \mathrm{kg} /$ day and metronidazole $21 \mathrm{mg} / \mathrm{kg} /$ day) before referral to the eye clinic, so he continued on them while some investigations were requested. Some tests (skull $x$-ray, FBC, ESR and blood film plus eye swab for microscopy/culture/ sensitivity) were already ordered by the paediatricians though none had been done when the patient came to the clinic. An orbital CT scan was immediately ordered but due to financial constraints this could not be done, instead an oculo-orbital ultrasound scan was done. On B-scan ultrasonography, a huge right ocular mass, solid in consistency with heterogeneous architecture and which appeared to be growing from the superior margin of the globe was seen. The mass compressed the lens and anterior chamber making the structures indistinguishable. The appearance was suggestive of retinoblastoma.

Apart from a raised ESR $(85 \mathrm{~mm} / \mathrm{hr})$, other haematological and chemical pathological results were within normal limits. Due to the rapidly progressive and necrotic nature of the tumour (fig. 2), a lid-sparing modified exenteration was done. At surgery, the vitreous popped out and was found to be clear. The immediate post-operative period was uneventful but two and a half weeks after surgery, there was a recurrence of the tumour in the right orbit.

The histopathology reported a 3-piece irregularly shaped tissue; the largest measuring $6 \times 4.5 \times 4 \mathrm{~cm}$ and the smallest $2.5 \times 1.5 \times 1 \mathrm{~cm}$. On gross examination of the cut surface, a necrotic mass with areas of haemorrhage and cavitation were seen.
Microscopic examination revealed round blue cells with hyperchromic pleomorphic nuclei and scanty cytoplasm, arranged in sheets and crossed by fibrous bands. No rosettes were seen, rather areas of tumour necrosis were observed. These findings were consistent with a diagnosis of undifferentiated retinoblastoma.

About three weeks after surgery and following recurrence of the tumour in the right inferior orbit, the patient was commenced on chemotherapy by the paediatricians (Vincristine, Actinomycin D and Cyclophosphamide). A week after commencing chemotherapy, the tumour started to regress only to recur one month later (fig. 3).

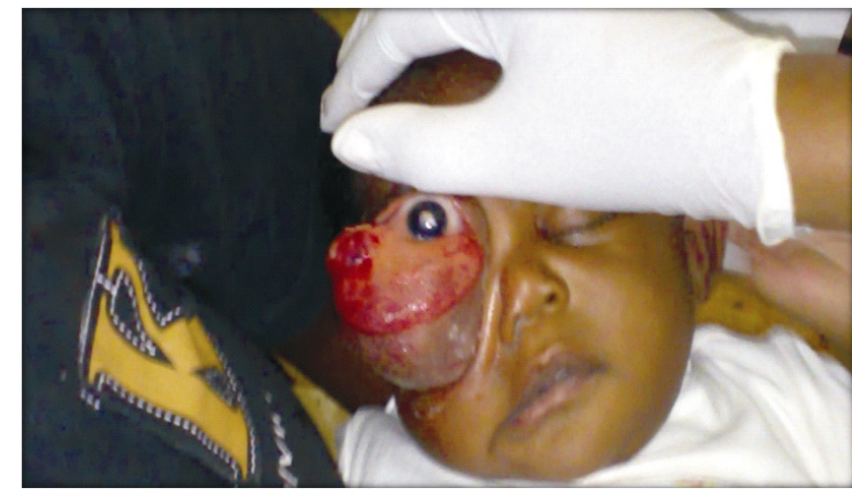

Figure 1. Baby GJ (17 ${ }^{\text {th }}$ April 2008)

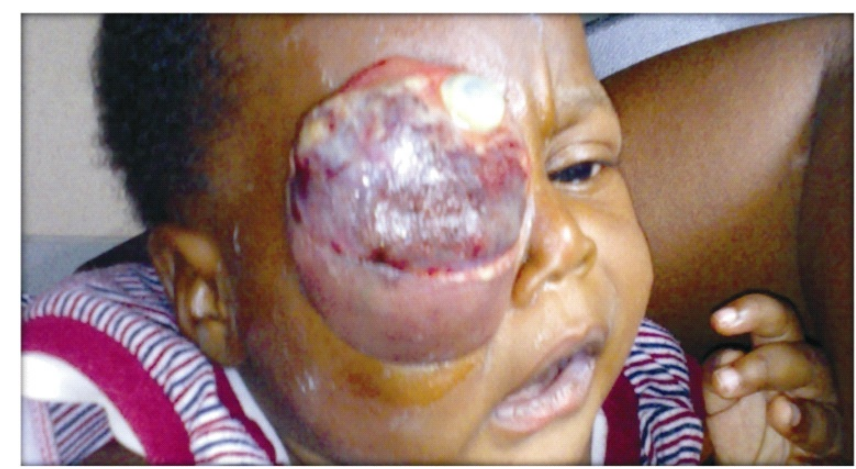

Figure 2. Baby GJ (21 ${ }^{\text {st }}$ April 2008)

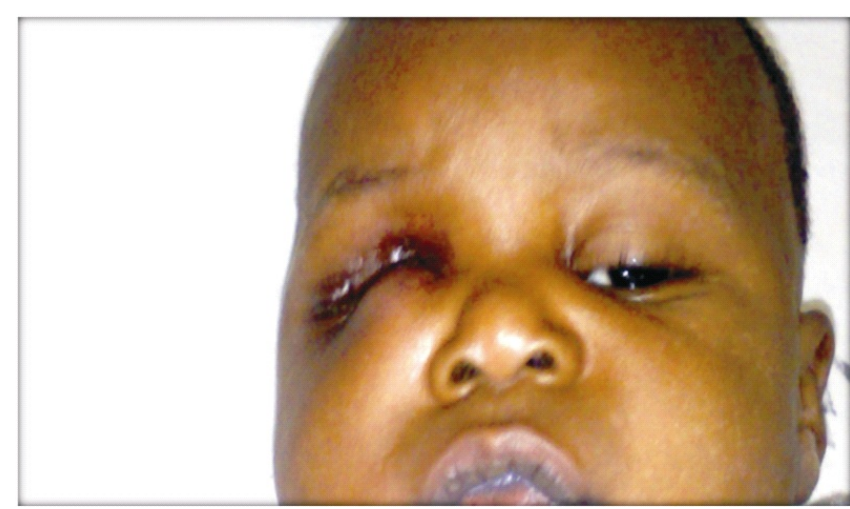

Figure 3. Orbital recurrence following modified exenteration and chemotherapy $\left(21^{\text {st }}\right.$ May 2008) 
The chemotherapeutic regimen was changed to etoposide, vincristine and carboplatin but this did not halt tumour progression. Despite aggressive chemotherapy, it continued to increase in size and invaded the right nasal cavity. The patient eventually died in October 2008.

\section{DISCUSSION}

Heritable retinoblastoma presents earlier compared to sporadic cases. ${ }^{11}$ This case had no family history, but due to the early presentation was initially considered to be heritable (spontaneous germ-line mutation).

Retinoblastoma is usually diagnosed during the first three years of life, with the average age of diagnosis being 18 months. It is almost never found at birth except when there is a positive family history, which usually prompts an early fundus examination. Familial retinoblastoma has been diagnosed as early as 1-2 weeks after birth ${ }^{12}$ and within the first 3-4 months of life. ${ }^{13}$ In Nigeria it has been found to occur in babies as young as 5 months old ${ }_{1}^{14}$ though the mean age at diagnosis is about 33 months ${ }^{14,15}$ with bilateral neoplasia presenting in much younger children than unilateral disease. ${ }^{15,16}$ Studies have shown that about two-thirds of cases of bilateral retinoblastoma present within the first 6 months of life compared to one-third of cases for unilateral disease. $^{10}$

To the best of our knowledge, no case of unilateral retinoblastoma with a rapidly progressive proptosis has been reported in Nigeria, though elsewhere congenital advanced unilateral retinoblastoma had been reported in a newborn who had no family history of retinoblastoma. ${ }^{17}$

There are numerous reports of unusual presentations of retinoblastoma in the literature. ${ }^{17-19}$ A rare case of retinoblastoma presenting as a congenital primary intracranial tumour was reported in a 7-day-old infant who presented with generalized seizures and had a family history of retinoblastoma. ${ }^{18}$ Another case of bilateral congenital retinoblastoma was reported in a 2-month old baby in Brazili ${ }^{19}$ the right eye was phthisical. Many cases of retinoblastoma occurring in a microophthalmic eye have also been reported in the literature..$^{20-24}$ Most reported cases of congenital retinoblastoma have been outside the Africa continent. ${ }^{3,6,7,18,19}$ In patients with unilateral retinoblastoma, the risk of the hereditary form is about $10 \%$. Thus, patients with both bilateral and hereditary unilateral diseases are at high risk $(45 \%)$ of having offspring with retinoblastoma. ${ }^{12}$ Parents whose children are at risk of developing retinoblastoma therefore require careful counselling with regard to the likelihood of tumour development and visual sequelae and the likelihood of fatality. ${ }^{12}$

This case was poorly-differentiated and agrees with previous studies which indicate that poorly-differentiated retinoblastoma is more common among African children than well-differentiated retinoblastoma. ${ }^{15,16}$ Though conservative modalities can now be successfully applied in small tumours, the advanced stage of the disease at presentation meant that modified exenteration was the only option in this case. This treatment modality (lid-sparing modified exenteration with chemotherapy) is similar to the other cases reported. ${ }^{14,17,19}$

Postoperative tumour recurrence has been found to be more common in bilateral cases. ${ }^{25}$ This case however differed; though unilateral, it had early postoperative recurrence. Studies have also shown that a good number of patients who had unilateral disease diagnosed in the first 6 months of life subsequently developed bilateral disease. ${ }^{10,26}$

About two weeks after surgery, there was tumour recurrence but this regressed following commencement of chemotherapy. The patient developed further recurrence despite aggressive chemotherapy and eventually died in October 2008

\section{CONCLUSION}

Retinoblastoma in Third World countries is still a fatal disease compared to developed countries where the survival rate is over $90 \%$. Poverty and non availability of sophisticated diagnostic tools make early detection difficult thus increasing mortality from the disease.

\section{ACKNOWLEDGEMENTS}

We wish to acknowledge all staff of the Paediatric Oncology Unit (headed by Dr (Mrs) N Akani) of the University of Port Harcourt Teaching Hospital for their input in the management of this patient.

\section{REFERENCES}

1. Yanoff M, Duker JS: Ophthalmology. Mosby St Louis. 2004, p. 1043.

2. Bishop JO, Madsen EL. Retinoblastoma: Review of the current status. Surv Ophthalmol 1975; 19: 342-366.

3. Sanders BM, Draper GJ, Kingston JE. Retinoblastoma in Great Britain 1969-80: Incidence, treatment and survival. $\mathrm{Br} \mathrm{J}$ Ophthalmol 1988; 72: 576-583.

4. Abramson DH, Notterman RB, Ellsworth RM, Grumbach N, Buckhout LS, Halk BG. Retinoblastoma: correlation between age at diagnosis and survival. J.Pediatr Ophthalmol Strabismus 1986; 23: 174-177.

5. Kodilinye HC. Retinoblastoma in Nigeria: problem of treatment. Am J Ophthalmol 1967; 63:.469-481.

6. Ellsworth RM.The practical management of retinoblastoma. Trans Am Ophthalmol Soc 1969; 67:.462-534.

7. Shields JA. Diagnosis and management of intraocular tumours. CV Mosby St Louis 1983, p. 439.

8. Tarkkanen A, Tuovinen E. Retinoblastoma in Finland 19121964. Acta Ophthalmol 1971; 49: 293-300.

9. Abramson DH, Servodidio CA. Retinoblastoma in the first year of life. Ophthalmic Paediatr Genet 1992; 13: 191-203.

10. Abramson DH, Notterman RB, Ellsworth RM, Kitchin FD. Retinoblastoma treated in infants in the first six months of life. Arch Ophthalmol 1983; 101: 1362-1366.

11. Murphee AL, Munier FL. Retinoblastoma: In Ryan SJ, ed. Retina $2^{\text {nd }}$ edition, St Louis : Mosby Yearbook, 1994; Vol. 1, 
Chap 27

12. Imhof SM, Moll AC, Schouten-van Meeteren AYN. Stage of presentation and visual outcome of patients screened for familial retinoblastoma: nationwide registration in the Netherlands. Br J Ophthalmol 2006; 90: 875-878.

13. Leal-Leal CA, Rivera-Luna R, Flores-Rojo M, JuárezEchenique JC, Ordaz JC, Amador-Zarco J. Survival in extraorbital metastatic retinoblastoma: treatment results. Clin Transl Oncol 2006; 8: 39-44.

14. Ezepue UF, Madufa-Okafor C. Retinoblastoma: a review of occurrence, available treatment and prognosis at Enugu. Niger J Ophthalmol 1995; 3(2):1-5.

15. Akang EE, Ajaiyeoba IA, Campbell OB, Olurin IO, Aghadiuno PU. Retinoblastomas in Ibadan, Nigeria :II-Clinicopathologic features. West Afr J Med 2000; 19: 6-11.

16. Mukhtar AU, Kagame K. Pathological study of retinoblastoma in Mbarara, Uganda. Cent Afr J Med 2000; 46: 13-16.

17. Plotsky D, Quinn G, Eagle R Jr, Shields J, Granowetter L. Congenital retinoblastoma: a case report. J Pediatr Ophthalmol Strabismus 1987; 24(3): 120-123.

18. Al Omari A, Mustafa M M, Hessler R, Rejjal A, Kattan A. Retinoblastoma as congenital primary intracranial tumor. $J$ Pediatric Hematology/Oncology 1999; 21(4): 296-298.
19. Ana Beatriz Sacchetto Ungaro ABS, Cunha SL, Santo RM. Congenital retinoblastoma - Report of a case. Arq Bras Oftalmol 2002; 65:571-573.

20. Levine AR, Albert DM, Sang DN. Retinoblastoma with persistent hyperplastic vitreous. Invest Visual Sci 1997; 16: 403407.

21. Axelsen I. Retinoblastoma in a microphthalmic eye. Ophthalmologica 1978; 176: 27-33.

22. Morgan KS, McLean IW. Retinoblastoma and persistent hyperplastic vitreous occurring in the same patient. Ophthalmology 1981; 88: 1087-1090.

23. Liang JC, Augsburger JJ, Shields JA. Diffuse infiltrating retinoblastoma associated with persistent primary vitreous. J Pediatr Ophthalmol Strabismus 1985; 22: 31-33.

24. Jong SL, Young KS, Jung G. Retinoblastoma which developed in microphthalmia. Acta Ophthal 1997; 75: 730-731.

25. Ajaiyeoba IA, Akang EE, Campbell OB, Olurin IO, Aghadiuno PU. Retinoblastomas in Ibadan: treatment and prognosis. West Afr J Med 1993; 12(4): 223-227.

26. Abramson DH, Du TT, Beaverson KL. Retinoblastoma in the first month of life. Arch Ophthalmol 2002; 120: 738-742. 